\title{
Anatomy of the Kidneys and Urinary \\ Tract System
}

Figure 6.1 shows the anatomy of the kidneys and urinary tract system.

The urine constituents found in urine sediment are named according to their origin. From a diagnostic perspective, it is important to distinguish cells of renal origin from cells of post-renal origin. For example, the increased presence of dysmorphic erythrocytes and acanthocytes is attributed to impaired renal tissue or impaired glomeruli. Eumorphic erythrocytes are more likely to be of post-renal origin (exception: renal tumor). Casts form in the distal renal tubules depending on the $\mathrm{pH}$ value and concentration of the urine.

Epithelial cells are also named according to their origin. Renal and tubular epithelial cells are found in kidney tissue. Transitional epithelium/urothelium covers the renal pelvis and urinary tract system up to the upper segment of the urethra. The squamous epithelium originates in the lower segment of the urethra.

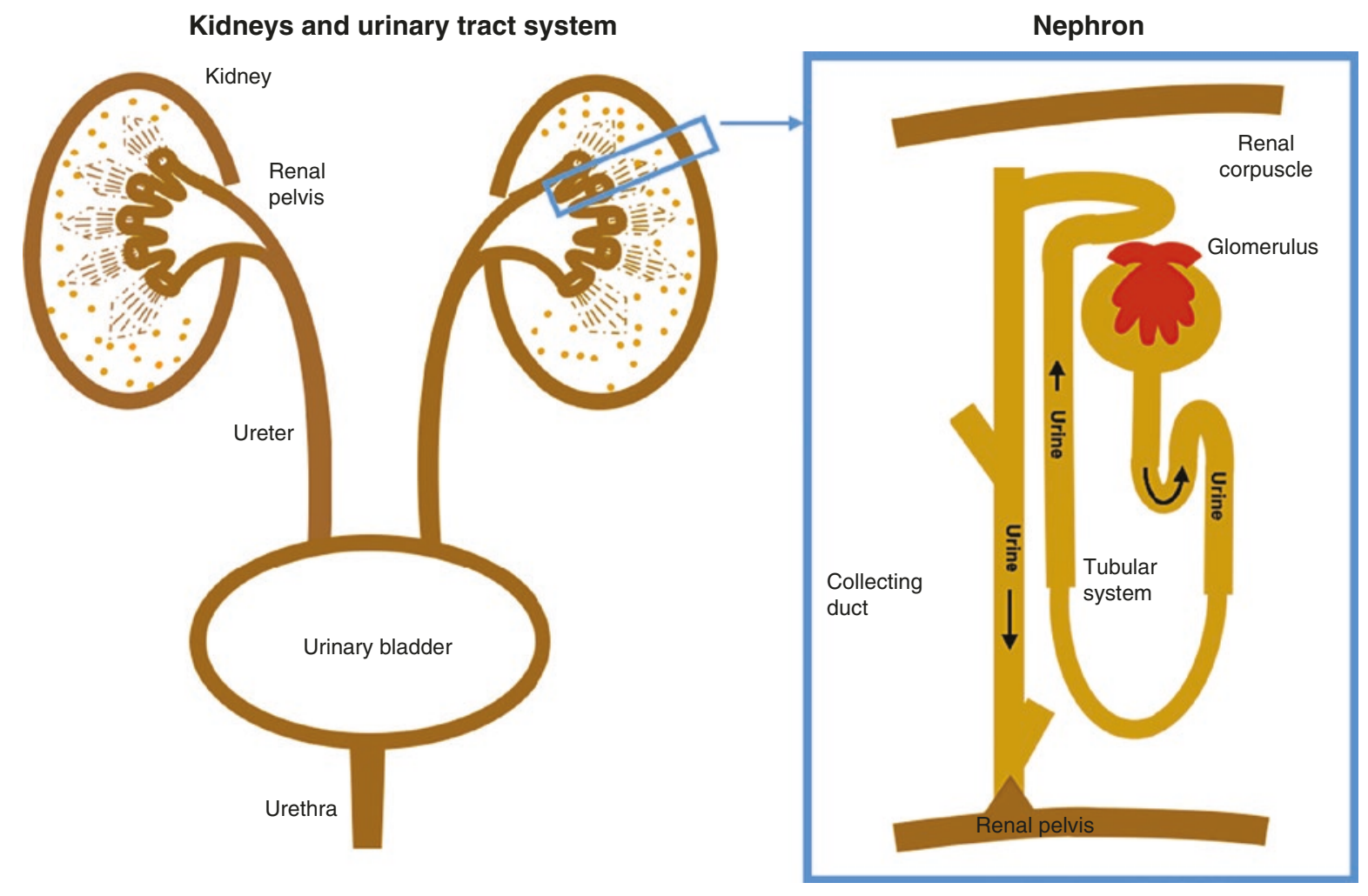

Fig. 6.1 Overview: anatomy of the kidneys, urinary tract system, and nephron 